\title{
An exploration of the extent of inclusion of spirituality and spiritual care concepts in core nursing textbooks
}

\author{
Fiona Timmins ${ }^{\mathrm{a}, *}$, Maryanne Murphy ${ }^{\mathrm{a}}$, Freda Neill ${ }^{\mathrm{a}}$, Thelma Begley ${ }^{\mathrm{a}}$, Greg Sheaf ${ }^{\mathrm{b}}$ \\ a The School of Nursing and Midwifery, Trinity College, Dublin, Ireland \\ b The Library, Trinity College, Dublin, Ireland
}

\section{A R T I C L E I N F O}

\section{Article history:}

Received 4 November 2013

Received in revised form 4 April 2014

Accepted 21 May 2014

Available online $\mathrm{xxxx}$

\section{Keywords:}

Nursing student

Textbook

Spirituality

Spiritual care

Spiritual

Assessment

\begin{abstract}
S U M M A R Y
Background: Holistic care that encompasses a spiritual dimension is an expectation in modern healthcare (Rothman, 2009). Increasing attention is being paid to the role of nurses in providing spiritual care to patients. However nurses lack specific skills and expertise in this area (Lundmark, 2006; Timmins, 2010; RCN, 2011), and the extent to which their undergraduate education prepares them for this role is unclear. There is often an absence of clear direction about what to teach undergraduate nursing students. The extent to which core textbooks direct student studies in this area is not known. There is some evidence that some of these fundamental core textbooks provide insufficient direction (Pesut, 2008), thus gaps in knowledge and care provision in this field could be exacerbated.

Aim: The aim of this study is to examine the extent to which spiritual care concepts are addressed in core nursing textbooks.

Methods: Five hundred and forty three books were sampled from the Nursing and Midwifery Core Collection list (UK) (Tomlinsons, 2010) representing $94 \%$ of the total $(n=580)$. A survey, the Spirituality Textbook Analysis Tool (STAT), was developed and used to collect data.

Findings: One hundred and thirty of the books included content related to spirituality and religion. However there was little consistency in the core nursing textbooks with regard to direction for providing spiritual care. Thirty eight percent of the books defined spiritual care and 36\% provided an outline of the role of the nurse in providing this. While some books advocated the assessment of patients' spiritual needs (32\%) few referred specifically to assessment tools.

Discussion: It is essential that nurses are adequately prepared to address the spiritual needs of patients. While there are numerous spiritual care texts that deal solely with this issue for nurses, there is an argument emerging that core nursing texts used by nursing students ought to encompass spiritual care elements. Lack of specific focus on this field, by these key textbooks might infer that this important element of holistic care is less important than other matters in nursing. True holistic care ought to permeate across textbooks and as such spirituality and spiritual care ought not to be sequestered to specialised texts. Core nursing texts need to be strengthened through consistency of application and inclusion of spirituality and spiritual care where relevant.
\end{abstract}

(c) 2014 Elsevier Ltd. All rights reserved.

\section{Introduction}

Holistic care that recognises the spiritual needs of patients is an expectation of modern healthcare (Rothman, 2009). Increasing attention is being paid to the role of nurses in providing spiritual care to patients (Timmins, 2010; Royal College of Nursing, 2011; Pesut and Sawatzky, 2006). It is important for nurses to take up this activity following specific guidance as to what it entails and how it should be done (Pesut and Sawatzky, 2006). However many nurses today lack specific knowledge and skills in this area (Lundmark, 2006; Timmins, 2010; Royal College of Nursing, 2011). Preparation for this role ought to form part

* Corresponding author at: School of Nursing and Midwifery Studies, 24, D' Olier Street, Dublin 2, Ireland. Tel.: + 35318963699.

E-mail address: fiona.timmins@tcd.ie (F. Timmins). of the undergraduate nursing curriculum (Li-Fen Wu et al., 2012; KhoramiMarekani et al., 2010; McSherry, 2006a). However, it is unclear what specific curricula content prepares the nurse for this role. Furthermore it is emerging that there is a lack of clear guidance from core nursing textbooks on this topic (Pesut, 2008). Indeed little is known about how much core textbooks contribute to nurses' understanding in this area.

\section{Literature Review}

\section{Definitions of Spirituality and Spiritual Care}

The literature abounds with definitions of spirituality, suggested interventions, and tools for assessments. While spirituality is often 
confused with religion, it is a broader holistic concept that transcends it (McSherry, 2006a). A commonly referred to definition is that of Narayanasamy (2004 P.1140) who suggests that spirituality:

"Gives us a sense of personhood and individuality. It is the guiding force behind our uniqueness and acts as an inner source of power and energy, which makes us 'tick over' as a person. Spirituality is the inner, intangible dimension that motivates us to be connected with others and our surrounding. It drives us to search for meaning and purpose, and establish positive and trusting relationships with others."

Sessanna et al. (2007) in a concept analysis categorised spirituality according to four main themes. These were:

1. a religious system of beliefs and values;

2. that which gives life meaning, purpose, and connection with others;

3. a non-religious system of beliefs and values; or

4. as metaphysical or transcendental phenomena.

Similarly, Vance (2001) having observed difficulties defining the concept, identified three similar elements that underpin most standard definitions of spirituality as: interconnectedness with God or god being, purpose and meaning of life, and the ability to transcend oneself.

Miner-Williams (2006) following a review of the literature devised an explanatory conceptual framework for spirituality comprising connectedness, meaning, transcendence, energy and emotion (Fig. 1).

Within this framework, there are some parallels to others in the literature specifically with Narayanasamy's (2004) definition of connectedness and Vance's (2001) categories of interconnectedness with a higher power; purpose and meaning of life; and the ability to transcend oneself. This framework attempts to encompass different expressions of spirituality. Expression of religion is interestingly described as a behavioural manifestation of spirituality. Religion and spirituality appear interlinked.

McSherry (2006b) provides another explanatory framework, which allows for understanding of spirituality within the health care context. It is called the Principal Components Model which arose from research interviews with 53 key including nurses, chaplains, patients, other health care workers and members of the public in the UK (Fig. 2). The principal components are individuality, inclusivity, integrated and inter/ intradisciplinary.

There appears to be a lack of consensus across the literature in terms of agreed definitions of spirituality (Pesut, 2008). However some argue that debate about definitions in this field is merely an academic exercise (Paley, 2008). Nonetheless, it is confusing for nurses unless one clear definition is used to guide practice. National guidelines while definite about the need for spiritual care are often remiss in providing key definitions (An Bord Altranais, ABA, 2009; NMC, 2012). However more recently in the UK quite clear direction in this field emerged (Royal College of Nursing, 2014). This suggests that spirituality is about meaning and purpose in life; forgiveness; belief and faith; finding sources of hope and strength in the midst of hopeless situations; learning to trust in something during the illness experience; confidence; values and love and relationships.

Spirituality is a primarily a cultural dimension of humanity (Health Services Executive (HSE), 2009; Bethal, 2004), and “meaning making” which is a human feature appears to underpin many of these popular definitions (la Cour and Hvidt, 2010). Assessment forms the basis of spiritual care and UK nurses are encouraged to use "meaning making" as a conceptual framework when providing spiritual care (Royal College of Nursing, 2011).

Usually understandings of spirituality inform spiritual assessment (Royal College of Nursing, 2011; McSherry and Jamieson, 2011; Narayanasamy, 1999). Current lack of knowledge, consistency and confidence with regard to spirituality definitions may hamper nurses' attempts at assessment. It could possibly even cause harm, if, without guidance, a nurse proffers her own spiritual views.

\section{Providing spiritual care}

The Royal College of Nursing (2014) also provides clear guidance about the provision of spiritual care, which centres on supporting patients with finding meaning, purpose and hope. A more detailed approach focuses on six core competencies (Van Leeuwen and Cusveller, 2004) that are said to underpin and inform spiritual nursing care these are:

- Handling one's own beliefs

- Addressing spirituality

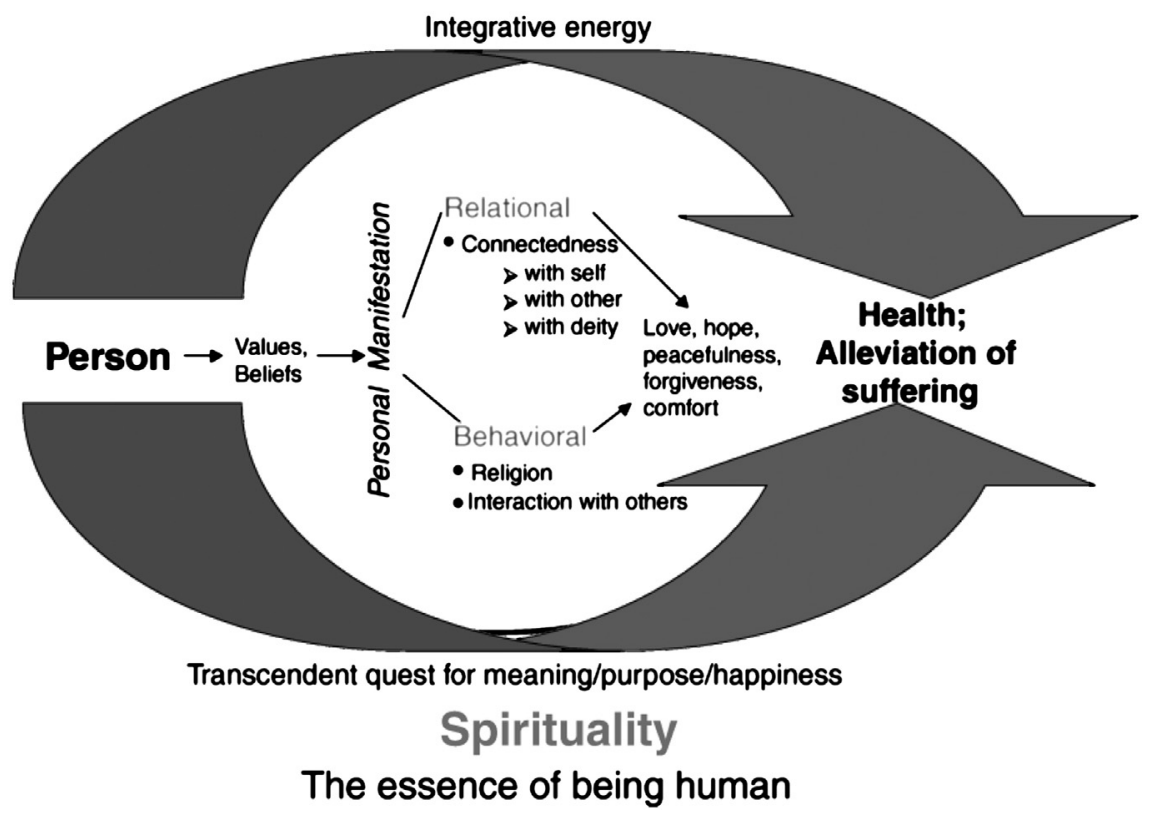

Fig. 1. Explanatory conceptual of human spirituality. Miner-Williams (2006). 


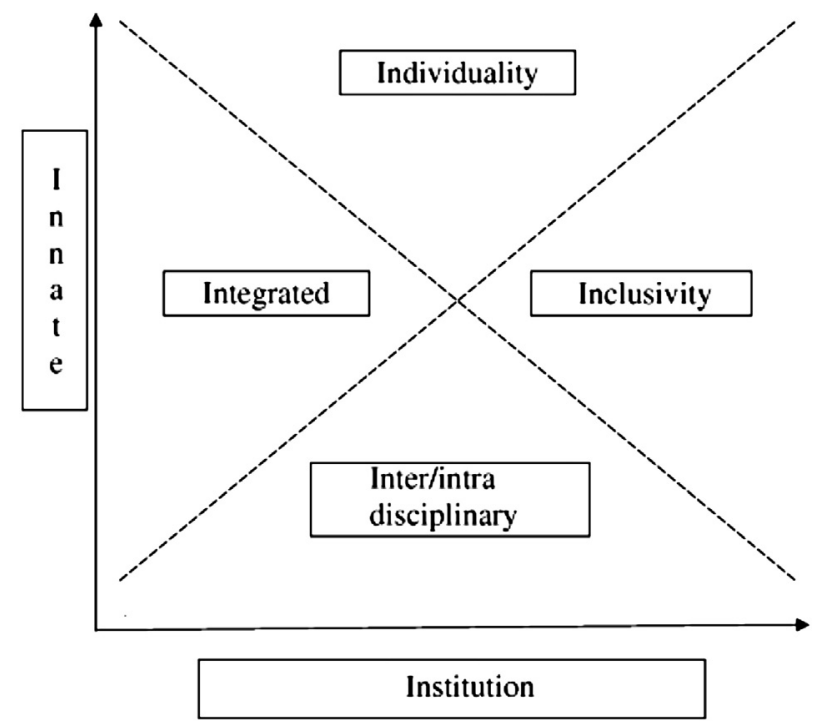

Fig. 2. The principal components model: an explanatory framework for understanding of spirituality within the health care context.

McSherry (2006b).

- Collecting spiritual assessment information,

- Discussing and planning spiritual interventions,

- Providing and evaluating spiritual care, and

- Integrating spirituality into institutional policy.

Collecting spiritual assessment information is a fundamental part of the nurses' role in this area. It is useful if this is done using a process approach whereby the nurse assesses, plans, implements, and evaluates spiritual care (O'Shea et al., 2011; Baldacchino, 2011). Spiritual assessment tools may be used by health care staff and a number of these exist (Timmins and Kelly, 2008). However assessment tools may be overly cumbersome and time consuming for acute clinical settings, and their abundance and lack of testing may cause further confusion for practising nurses (Timmins and Kelly, 2008). Nonetheless assessment permits some standardisation in approaches to care and whether they are used is a matter for local hospital, nursing policy and also chaplaincy teams. It has also been acknowledged that assessment has primarily been the domain of chaplains (Buswell et al., 2006; Hunt et al., 2003) but nurses should work closely with them (Buswell et al., 2006; McSherry and Ross, 2002) in order to fully support patients in their care.

An informal assessment, without using a specific tool, is becoming more popular. Patients are encouraged to talk about the "story of their illness and admission" (Power, 2006), or spiritual beliefs (Tanyi, 2006) while at the same time the nurse observes for particular cues about spirituality (McSherry and Ross, 2002). This narrative and observation method is thought to be more suitable than a formalised assessment (Power, 2006), and seems favoured contemporarily (Royal College of Nursing, 2011).

\section{Learning About Spirituality and Spiritual Care}

There is some agreement that spirituality needs to form part of the undergraduate curriculum (Li-Fen Wu et al., 2012; KhoramiMarekani et al., 2010; McSherry, 2006a). Existing curricular guidelines and nurse codes support this (An Bord Altranais, ABA, 2009; NMC, 2012). However approaches vary and significant gaps exist in provision (McSherry, 2006a). While many universities teach spirituality to health care students there is a both a lack of clarity and consensus about what is actually taught (Koenig et al., 2012).

Some authors hold the view that spirituality learning occurs ultimately in the practice setting (McSherry, 2006a; Bradshaw, 1994). As such, spirituality is viewed as something that is learned in practice rather than explicitly taught. Thus, there are no recognised or consistent approaches to the teaching of spirituality to undergraduate nursing students (McSherry, 2006a). The extent to which guidance about spiritual care is included in core textbooks for nursing students may influence this. Therefore it is important for nurse educators to determine the extent that spirituality is included in core nursing texts.

Pesut (2008) performed the only examination of this area and scrutinised ten US Nursing textbooks all of which contained the term "fundamentals" in the title. This author found that throughout these books understandings of spirituality were inconsistent and unclear. There was also a lack of consensus on definitions. This in an important finding as inconsistent use and application of spiritual care understandings can impact upon the nurse's ability to incorporate spirituality as an essential component of care for patients and families (Sessanna et al., 2007). Pesut (2008) also suggests that many textbooks did not sufficiently address this issue, and as such the area could be totally overlooked by nurses and nursing students.

However beyond this single site US study, there is little information about the content of current core nursing textbooks. It is unclear as to the extent to which approaches advocated within them espouse spiritual care within the context of holistic care, or how authoritative/prescriptive these texts actually are. While there are several books that address spirituality, it would be of interest to examine the extent to which core general nursing textbooks address this topic, as these are more frequently used by the nursing student population. In the context of the absence of clear direction about what to teach undergraduate nursing students, the lack of conceptual clarity around definitions, and suggestions that nurses perform spiritual assessment this study aims to explore the extent to which current core nursing textbooks support and advocate spiritual care delivery by nurses and nursing students.

\section{Methods}

The aim of the study was:

- To examine the extent to which spiritual care concepts are addressed in core nursing textbooks.

The objectives of the study were as follows:

- To determine whether or not core undergraduate nursing textbooks include terms related to spirituality or spiritual care.

- To examine whether or not core nursing textbooks define spirituality or spiritual care or the core elements of spirituality.

- To examine the extent to which core nursing textbooks advocate spiritual assessment by nurses.

\section{Method of Data Collection}

A 23 item survey was devised by the research team that comprised five University Staff including one nursing subject librarian during a series of team meetings. As there was no pre-existing tool, the Spirituality Textbook Analysis Tool (STAT) was specifically designed for this purpose. The STAT was developed by the research team over a period of three months. Several meetings were held to discuss the tool's potential usefulness to address the study aims, and a literature review (Timmins and Neill, 2013) underpinned its content development. Several iterations of the tool were developed and refined by the team before final completion. A pilot study also assisted with further refinement.

The tool aimed to capture information about the inclusion of spirituality, definitions, use of assessment and overall approach to spirituality in nursing texts. The instrument was used in the first instance to identify core textbooks which referred to spirituality by checking whether or not the following keywords were present in the index: spirituality; spirit; religion; transcendence; god; sacred; meaning and religious belief/s. These terms were determined by literature searching (Timmins and Neill, 2013), agreement within the team and pilot testing. Following 
this the questions ask about more specific issues related to spirituality inclusions.

This quantitative approach was deemed particularly beneficial as a quick method of generating useful information on data patterns and trends in the textbooks (Burns and Grove, 2011). The use of large numbers, suggested by this approach, also meant that results could be generalised (Burns and Grove, 2011). The 23 items in the survey contained a number of subsections comprising mostly closed questions; with yes/no responses and also including a small number of closed questions that invited the researchers to respond using a four-point Likert scale. The research team collected the data at one University Library site, which is a copyright library for Ireland and the UK.

The following definitions underpinned the study:Spirituality: Aspects of human existence that provide meaning and purpose to life (Narayanasamy, 2004).Religion: Belief in a higher power and with an outward practice of a spiritual understanding through the use of frameworks for a system of beliefs, values, codes of conduct and rituals (Koenig et al., 2012).

\section{Inclusion/Exclusion Criteria}

All books from the Nursing and Midwifery Core Collection list (UK) (Tomlinsons, 2010) $(n=580)$ were eligible for inclusion. Texts were excluded on the basis that they either (a) did not have an index or (b) were not available to the researchers. Five books were excluded on the basis of no index and 32 were unavailable. Therefore, five hundred and forty three books (543) were sampled from the Nursing and Midwifery Core Collection list (UK) (Tomlinsons, 2010) representing $94 \%$ of the total collection $(n=580)$.

\section{Validity and Reliability}

Content validity was assessed using criteria recommended by Polit and Tatano Beck (2012). Content validity of the audit tool was established by presenting the tool to a panel of eight experts internationally in the field, who were asked to rate the relevance of each question and sub-question ( $\mathrm{n}=58$ ). Polit and Tatano Beck (2012) do not provide guidance on determining experts for this validity texting. However these experts were derived from those names appearing consistently within the literature on the topic. Only those who were willing to take part and who performed the content validity assessment within the given timeframe were included.

In keeping with Polit and Tatano Beck's (2012) approach to content validity assessment reviewers were asked to rate the relevance of each on the tool using a scale of 1-4 (not relevant; somewhat relevant; quite relevant; highly relevant). Responses were collected using surveymonkey $\Subset$. Calculations of mean scores revealed an overall content validity average index (S-CVI/Ave) of 0.90 . A score of 0.90 or above is required for the tool to be at an acceptable validity level (Polit and Tatano Beck, 2012). The initial S-CVI (Scale Content Validity Index) score S-CVI was 0.63 . This reflects universal agreement; and needs to be above .80 (Polit and Tatano Beck, 2012). However Polit and Tatano Beck (2012) deem this a too stringent measurement. However the I-CVI (Item Content Validity Index) for each individual item is best to be above 0.80 for individual items (Polit and Tatano Beck, 2012) and as twelve items did not score above this, and upon review most of these items were deemed not relevant to the study and subsequently removed. All low scorers (except Q4 "state category number" - which was required for data collection purposes) were thus removed and the tool then satisfied the more stringent validity criteria with an S-CVI of .80 .

\section{Data Analysis Methods}

Quantitative data were analysed using the Statistical Package for Social Scientists (SPSS) database where a combination of descriptive and inferential statistics were applied to the data.
Table 1

Frequencies of search terms isolated within the index of the sample.

\begin{tabular}{llll}
\hline & Terms & Spirituality & Religion \\
\hline Frequency of search terms & Nil & $34.6 \%$ & $37.7 \%$ \\
& Once & $23.8 \%$ & $20.8 \%$ \\
& $2-4$ times & $15.4 \%$ & $19.2 \%$ \\
& $5-10$ times & $6.9 \%$ & $5.4 \%$ \\
& More than 10 times & $19.2 \%$ & $16.9 \%$ \\
\hline
\end{tabular}

\section{Ethical Issues}

Consent and confidentiality are not applicable to this project, as the data exists in the public domain. However the ethical principles of beneficence and non-maleficence were adhered to throughout the study, and in particular in the writing up of the published paper to ensure that authors/publishers/universities and other personnel are not unduly negatively represented.

\section{Findings}

The majority of books in the nursing core collection ( $n=41376 \%$ ) made no reference to the selected spirituality related terms. Only 130 (24\%) of the text books contained one or more of the selected terms in the index. The majority of these books ( $n=119,91.5 \%)$ were adult nursing books, and the remainder ( $\mathrm{n}=118.5 \%$ ) were child focused. Most were published in the UK ( $\mathrm{n}=8767 \%$ ); $30 \%$ were published in the USA ( $\mathrm{n}=39$ ) and the remainder were published elsewhere. Of these 130 textbooks, 85 (65.3\%) referred to aspects of spirituality (in the index). Of these 25 (19.2\%) had more than 10 different referrals to the term 'spirituality'; 9 (7\%) had 5-10 referrals; 20 (15.5\%) had 2-4 and 31 (24\%) referred to the term 'spirituality' only once (Table 1 ). Eighty one (62.3\%) of the 130 books made reference to religion in the index (Table 1$)$. Twenty two books $(16.9 \%)$ of these referred to the term 'religion' in the index on more than 10 occasions; 7 (5.4\%) on 5-10 occasions; 25 (19.2\%) on 2-4 occasions and 27 (20.8\%) on one occasion only (Table 1$)$.

Twenty (15.4\%) of the [130] textbooks dedicated one full chapter to the topic of spirituality whereas 43 (33\%) contained no discussion of spirituality within the text (Table 2). Twenty one (16.3\%) had less than one page discussing spirituality and 32 (24\%) had between two and four pages. Four (3\%) books presented one full chapter on the subject of religion (Table 3 ).

Only 41 (38.1\%) of the [130] textbooks provided a description of spiritual care and 46 (35.7\%) provided an outline of the role of the nurse in providing this care. Forty one (31.5\%) [of the 130 textbooks] suggested spiritual care assessment as a component of care and 48 (37.2\%) suggested referring patients to a chaplain or pastoral care worker as a key part of spiritual care. Thirteen different spiritual assessment tools were proposed. Very few of the $130(n=19,14.7 \%)$ indicated that a sacred space was a requirement of spiritual care provision. Fifty seven (44.2\%) of the 130 textbooks deemed spiritual care as relevant to all people and 21 (16.3\%) deemed it to be relevant to specific rituals that may occur in health care settings.

Table 2

Proportion of books dedicated to the topic of spirituality.

\begin{tabular}{ll}
\hline Proportion of books dedicated to spirituality & \\
\hline Nil & 43 books $(33.1 \%)$ \\
Less than 1 page & 21 books $(16.2 \%)$ \\
$2-3$ pages & 22 books $(16.9 \%)$ \\
$4-6$ pages & 10 books $(7.7 \%)$ \\
More than 6 pages & 14 books $(10.8 \%)$ \\
1 full chapter & 20 books $(15.4 \%)$ \\
Total books $=130$ & \\
\hline
\end{tabular}


Table 3

Proportion of included books dedicated to religion.

\begin{tabular}{lc}
\hline Proportion of books dedicated to religion & \\
\hline Nil & 26 books $(20 \%)$ \\
Less than 1 page & 45 books $(34.6 \%)$ \\
$2-3$ pages & 29 books $(22.3 \%)$ \\
$4-6$ pages & 14 books $(10.8 \%)$ \\
More than 6 pages & 12 books $(9.2 \%)$ \\
1 full chapter & 4 books $(3 \%)$ \\
Total books $=130$ & \\
\hline
\end{tabular}

Even if not specifically mentioned in the index, the majority of books (that referred to the topic) provided some discussion on the subject of spirituality ( $66.7 \% \mathrm{n}=86$ ) and the majority mentioned religion ( $\mathrm{n}=104,80.6 \%$ ) with some including information on a number of different religions. The most frequently cited religion was Christianity ( $\mathrm{n}=69,53.5 \%)$; followed by Islam $(\mathrm{n}=48,37.2 \%)$; Hinduism $(\mathrm{n}=$ 33, 25.6\%); Sikhism ( $\mathrm{n}=26,20.2 \%)$; Humanism $(\mathrm{n}=18,14 \%)$ and atheism ( $\mathrm{n}=16,12.4 \%)$ (Table 4$)$.

Some provided a description of the distinction between spirituality and religion ( $\mathrm{n}=43,33.3 \%)$, whereas many $(\mathrm{n}=75,58.1 \%)$ did not. In other cases $(\mathrm{n}=11,8.5 \%)$ this latter differentiation was unclear. Only 48 (37.2\%) provided a specific definition of spirituality (Fig. 3).

Findings revealed an overall lack of consistency with regard to the inclusion of spirituality and/or religion within core undergraduate nursing textbooks. While some advocate assessment of spiritual needs ( $n=41,32.5 \%$ ), few refer specifically to assessment tools (Fig. 4) and there was little overall consistency among those that did suggest their use.

\section{Discussion}

These findings reveal an overall lack of consistency with regard to the inclusion of spirituality concepts within core undergraduate nursing textbooks. It was surprising how few actually made reference to these issues. Many of these omissions were understandable as the core material perhaps did not lend itself to this (pharmacology for example) however there were also many surprising omissions.

Of the few books that mentioned the topic, some books advocated assessment of spiritual needs, few referred specifically to assessment tools and there was little overall consistency among those that did suggest their use. The plethora of suggested tools was not surprising and is a reflection of the multiple approaches suggested approaches in this area. However this may also be confusing for nurses and nursing students, and greater consistency would benefit both nurses and patients. Overall approaches were tokenistic, with few textbooks devoting substantial proportions of content to discussions. Minimal page coverage often mirrored a superficial and tokenistic approach to the topic. The number of citations within the index of the textbooks was often disproportionate to the number of pages devoted to the discussion, overall full chapters and substantial discussions of the topics were rare.

While there are several nursing textbooks available that deal directly with this topic, it is disappointing that less than one quarter of textbooks in the collection refer to the area. Given the increasing impetus internationally towards nurses providing spiritual care, and the growing cultural and religious diversities of client groups, it is essential that the nursing

Table 4

Religions cited in core nursing text books.

\begin{tabular}{lllc}
\hline & & Number (104) & Percentage \\
\hline Religion cited & Christianity & $\mathrm{N}=69$ & $53.5 \%$ \\
& Islam & $\mathrm{N}=48$ & $37.2 \%$ \\
& Hinduism & $\mathrm{N}=33$ & $25.6 \%$ \\
& Sikhism & $\mathrm{N}=26$ & $20.2 \%$ \\
& Humanism & $\mathrm{N}=18$ & $14 \%$ \\
& Atheism & $\mathrm{N}=16$ & $12.4 \%$ \\
\hline
\end{tabular}

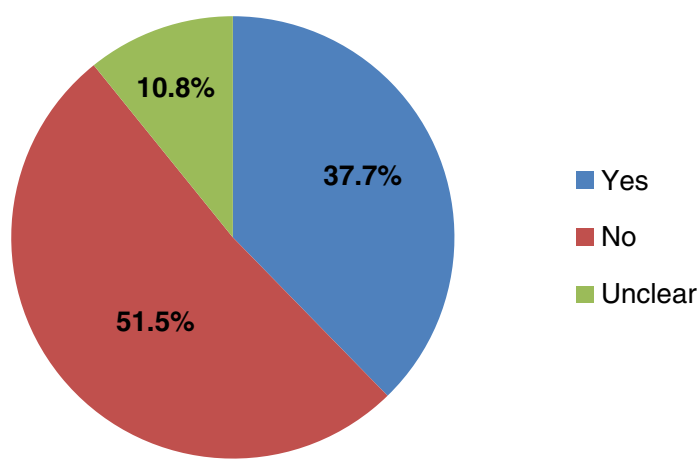

Fig. 3. Percentages of textbooks providing definitions of spirituality.

profession begins to understand and conceptualise what is meant by spirituality and spiritual care in order to adequately support patients (McSherry and Jamieson, 2011). However, it may prove difficult for students to assimilate these concepts into their learning if frequently used textbooks rarely refer to these concepts.

The absence of specific reference to spiritual care, which is deemed a core nursing skill (An Bord Altranais, ABA, 2009; NMC, 2012; International Council of Nurses, ICN, 2000) may inadvertently indicate that emphasis is not required in this area. Furthermore the tokenistic approach to the topic in these books may negate against holistic nursing practice, as readers are often guided towards consideration of spirituality and religion in a stereotypical way. If spirituality and addressing patients' spiritual needs are to be perceived as a component of holistic care then the discussion of this topic ought not to be confined to spiritual nursing care texts only. It ought to feature more consistently across core nursing textbooks.

The absence of spirituality in some core textbooks and inconsistent application in others is bound to reflect in the education of nurses. Many nurses report not receiving basic tuition in their nurse education programme and using their own experience and/or beliefs (McSherry and Jamieson, 2011; Timmins, 2010). The absence of a clear underpinning philosophy across core texts that embraces the notion of a holistic human with spiritual needs may serve to compound this problem.

\section{Conclusion}

As spirituality is espoused as an overarching human concept applicable to all, the inclusion of spirituality in nursing curricula needs to be expanded beyond specialised texts dealing with this topic. Students' reading of core texts needs to be strengthened through consistency of application and inclusion of the topics of spirituality and spiritual care where relevant. While there are numerous spiritual care texts that deal solely with this issue for nurses, lack of specific focus on this field, by these key textbooks may serve to minimise or compartmentalise

\section{Was Spiritual Assessment Proposed}

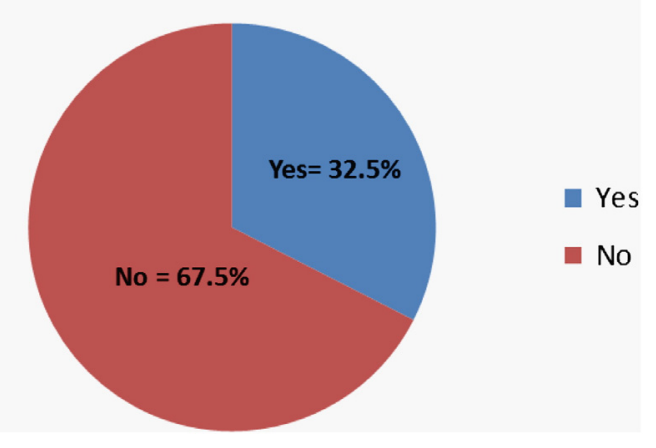

Fig. 4. Was spiritual assessment proposed? 
this important element of holistic care. True holistic care ought to permeate across textbooks. Spirituality and spiritual care ought not to be isolated to the extent that one has to seek out the information. Nor should it receive minimal and superficial attention in core textbooks. Textbooks supporting undergraduate student learning need to be more fully aligned with agreed conceptualisations of spirituality and unified approaches to spiritual care.

\section{References}

An Bord Altranais (ABA), 2009. An Bord Altranais Requirements and Standards for Nurse Registration Education programmes. An Bord Altranais, Dublin.

Baldacchino, D.R., 2011. Teaching on spiritual care: the perceived impact on qualified nurses. Nurse Educ. Pract. 11 (1), 47-53.

Bethal, J.C., 2004. Impact of social work spirituality courses on student attitudes, values, and spiritual wellness. J. Relig. Spiritual. Soc. Work Soc. Thought 23, 427-445.

Bradshaw, A., 1994. Lighting the Lamp: The Spiritual Dimension of Nursing Care. Scutari Press, London.

Burns, N., Grove, S.K., 2011. Understanding Nursing Research; Building an Evidence Approach Based, 6th edn Saunders, Philadelphia, Pa.; London.

Buswell, J., Clegg, A., Grant, F., Grout, G., Minardi, H.A., Morgan, A., 2006. Ask the experts. Spirituality in care. Gerontol. Care Pract. 18 (1), 14-15.

Health Services Executive (HSE), 2009. Health Services Intercultural Guide. Responding to the Needs of Diverse Religious Communities and Cultures in Healthcare SettingsHSE, Dublin, (Available online at: http://www.hse.ie/eng/services/Publications/services/ SocialInclusion/InterculturalGuide/Traditional/ accessed 7th March 2013).

Hunt, J., Cobb, M., Keeley, V.L., Ahmedzai, S.M., 2003. The quality of spiritual caredeveloping a standard. Int. J. Palliat. Care 9 (5), 208-215.

International Council of Nurses (ICN), 2000. Code of Ethics for Nurses. International Council of Nurses, Geneva.

KhoramiMarekani, A., Yaghmaie, F., Izadi, A., 2010. Instruction of spirituality and spiritual care in nursing: a challenge in curriculum development. J. Nurs. Midwifery 20 (68), 50.

Koenig, H.G., King, D., Carson, V.B., 2012. Handbook of Religion and Health, 2nd ed. Oxford University Press, Oxford.

la Cour, P., Hvidt, N.C.H., 2010. Research on meaning-making and health in secular society: secular, spiritual and religious existential orientation. Soc. Sci. Med. 71, 1292-1299.

Lundmark, M., 2006. Attitudes to spiritual care among nursing staff in a Swedish oncology clinic. J. Clin. Nurs. 15, 863-874.

McSherry, W., 2006a. The principal components model: a model for advancing spirituality and spiritual care within nursing and health care practice. J. Clin. Nurs. 15 (7), 905-917.

McSherry, W., 2006b. Making Sense of Spirituality in Nursing Practice. Jessica Kingsley, London.

McSherry, W., Jamieson, S., 2011. An online survey of nurses' perceptions of spirituality and spiritual care. J. Clin. Nurs. 20 (11-12), 1757-1767.

McSherry, W., Ross, L., 2002. Dilemmas of spiritual assessment: considerations for nursing practice. J. Adv. Nurs. 38 (5), 479-488.
Miner-Williams, D., 2006. Putting a puzzle together: making spirituality meaningful for nursing using an evolving theoretical framework. J. Clin. Nurs. 15 (7), 811-821.

Narayanasamy, A., 1999. ASSET: a model for actioning spirituality and spiritual care education and training in nursing. Nurse Educ. Today 19 (4), 274-285.

Narayanasamy, A., 2004. The puzzle of spirituality: a guide to practical assessment. Br. J. Nurs. 13 (19), 1140-1145.

NMC, 2012. Standards of proficiency for pre-registration nursing education. Nursing and Midwifery council, London, (available at: http://standards.nmc-uk.org/ PreRegNursing/statutory/competencies/Pages/Competencies.aspx accessed October 17th 2012).

O'Shea, E.R., Wallace, M., Griffin, M.Q., Fitzpatrick, J.J., 2011. The effect of an educational session on pediatric nurses' perspectives toward providing spiritual care. J. Pediatr. Nurs. 26 (1), 34-43.

Paley, 2008. Spirituality and secularization: nursing and the sociology of religion. J. Clin Nurs. 17 (2), 175-186.

Pesut, B., 2008. Spirituality and spiritual care in nursing fundamentals textbooks. J. Nurs Educ. 47 (4), 167-173.

Pesut, B., Sawatzky, R., 2006. To describe or prescribe: assumptions underlying a prescriptive nursing process approach to spiritual care. Nurs. Inq. 13 (2), 127-134.

Polit, D.F., Tatano Beck, C., 2012. Nursing Research Generating and Assessing Evidence for Nursing Practice. Lippincott Williams and Williams, London.

Power, J., 2006. Spiritual assessment: developing an assessment tool. Nurs. Older People 18 (2), 16-18.

Rothman, J., 2009. Spirituality: what we can teach and how we can teach it. J. Relig Spiritual. Soc. Work Soc. Thought 28 (1-2), 161-184.

Royal College of Nursing, 2011. RCN Spirituality in Nursing Care: A Pocket Guide. RCN London.

Royal College of Nursing, 2014. Spirituality in Nursing Care: Online Resource. available at http://www.rcn.org.uk/development/practice/spirituality/about_spirituality_ in_nursing_care (accessed 1st April 2014).

Sessanna, L., Finnell, D., Jezewski, M.A., 2007. Spirituality in nursing and health-related literature. J. Holist. Nurs. 25 (4), 252-262.

Tanyi, R.A., 2006. Spirituality and family nursing: spiritual assessment and intervention for families. J. Adv. Nurs. 53 (3), 287-294.

Timmins, F. (2010) An Exploration of nurse's attitudes to spirituality within an acute hospital setting. Nursing Adelaide Society Nursing Development Fund 2007-2008 Dublin: Unpublished report.

Timmins, F., Kelly, J., 2008. Spiritual assessment in intensive and cardiac care nursing Nurs. Crit. Care 13 (3), 124-131.

Timmins, F., Neill, F., 2013. Teaching nursing students about spiritual care - a review of the literature. Nurse Educ. Pract. 3 (6), 499-505.

Tomlinsons, 2010. Nursing and Midwifery Core Collection, 4th ed. Tomlinsons, London.

Van Leeuwen, R., Cusveller, B., 2004. Nursing competencies for spiritual careJ. Adv. Nurs. $48,234-246$.

Vance, D.L., 2001. Nurses' attitudes towards spirituality and patient care. Medsurg Nurs. 10 (5), 264-268.

Wu, Li-Fen, Liao, Yu-Chen, Yeh, Dah-Cherng, 2012. Nursing student perceptions of spirituality and spiritual care. J. Nurs. Res. 20 (3), 219-227. 